\title{
Nimesulide, a cyclooxygenase- 2 selective inhibitor, suppresses obesity-related non-alcoholic fatty liver disease and hepatic insulin resistance through the regulation of peroxisome proliferator-activated receptor $\gamma$
}

\author{
SHUNSUKE TSUJIMOTO ${ }^{1,2}$, MANABU KISHINA ${ }^{3}$, MASAHIKO KODA ${ }^{3}$, YASUTAKA YAMAMOTO ${ }^{2}$, \\ KOHEI TANAKA ${ }^{1}$, YUSUKE HARADA ${ }^{1}$, AKIO YOSHIDA ${ }^{1}$ and ICHIRO HISATOME ${ }^{1}$

\begin{abstract}
${ }^{1}$ Department of Genetic Medicine and Regenerative Therapeutics, Institute of Regenerative Medicine and Biofunction, Tottori University Graduate School of Medical Science, Yonago, Tottori 683-8504; ${ }^{2}$ Pharmaceutical Research Group II, Pharmacology Research Department, Pharmaceutical Development Research Laboratories, Tokyo 191-8512; ${ }^{3}$ Second Department of Internal Medicine, Tottori University, Yonago, Tottori 683-8504, Japan
\end{abstract}

Received March 22, 2016; Accepted June 30, 2016

DOI: $10.3892 /$ ijmm.2016.2674

\begin{abstract}
Cyclooxygenase (COX)-2 selective inhibitors suppress non-alcoholic fatty liver disease (NAFLD); however, the precise mechanism of action remains unknown. The aim of this study was to examine how the COX-2 selective inhibitor nimesulide suppresses NAFLD in a murine model of high-fat diet (HFD)-induced obesity. Mice were fed either a normal chow diet (NC), an HFD, or HFD plus nimesulide (HFD-nime) for 12 weeks. Body weight, hepatic COX-2 mRNA expression and triglyceride accumulation were significantly increased in the HFD group. Triglyceride accumulation was suppressed in the HFD-nime group. The mRNA expression of hepatic peroxisome proliferator-activated receptor $\gamma(\operatorname{PPAR} \gamma)$ and the natural PPAR $\gamma$ agonist 15 -deoxy- $\Delta^{12,14}$-prostaglandin $\mathrm{J}_{2}\left(15 \mathrm{~d}-\mathrm{PGJ}_{2}\right)$ were significantly increased in the HFD group and significantly suppressed in the HFD-nime group. Glucose metabolism was impaired in the HFD group compared with the NC group, and it was significantly improved in the HFD-nime group. In addition, the plasma insulin levels in the HFD group were increased compared with those in the NC group, and were decreased in the HFD-nime group. These results indicate that HFD-induced NAFLD is mediated by the increased hepatic expression of COX-2. We suggest that the production of $15 \mathrm{~d}-\mathrm{PGJ}_{2}$, which is mediated by COX-2, induces NAFLD and hepatic insulin resistance by activating PPAR $\gamma$. Furthermore, the mRNA expression of tissue inhibitor of
\end{abstract}

Correspondence to: Professor Masahiko Koda, Second Department of Internal Medicine, Tottori University, 36-1 Nishi-cho, Yonago, Tottori 683-8504, Japan

E-mail: masakoda@grape.med.tottori-u.ac.jp

Key words: cyclooxygenase-2, nimesulide, non-alcoholic fatty liver disease, insulin resistance, peroxisome proliferator-activated receptor $\gamma$, hepatic fibrosis metalloproteinases-1 (TIMP-1), procollagen-1 and monocyte chemoattractant protein-1 (MCP-1), as well as the number of F4/80-positive hepatic (Kupffer) cells, were significantly increased in the HFD group compared with the NC group, and they were reduced by nimesulide. In conclusion, COX-2 may emerge as a molecular target for preventing the development of NAFLD and insulin resistance in diet-related obesity.

\section{Introduction}

Non-alcoholic fatty liver disease (NAFLD) and non-alcoholic steatohepatitis (NASH), the advanced stage of NASH, are common conditions associated with insulin resistance and metabolic syndrome (1-3). In addition, NAFLD is associated with an increased risk of cardiovascular disease (4). Under fasting conditions, the liver produces glucose via gluconeogenesis in order to maintain blood glucose at a constant level (5). After meals, insulin converts glucose into glycogen and suppresses gluconeogenesis to maintain the level of glycemia (6). However, in patients with NAFLD, insulin cannot suppress gluconeogenesis and does not convert glucose to glycogen after meals, a condition known as hepatic insulin resistance. Previous studies found that the excessive hepatic accumulation of triglycerides (TGs) and free fatty acids (FFAs) induced hepatic insulin resistance $(7,8)$.

Peroxisome proliferator-activated receptor $\gamma(\operatorname{PPAR} \gamma)$ is a member of the nuclear hormone receptor superfamily (9). PPAR $\gamma$ is abundantly expressed in adipose tissue and plays a key role in lipid metabolism (10). Drugs activating PPAR $\gamma$ such as thiazolidinediones (TZDs) reverse NAFLD $(11,12)$. However, previous studies have shown that PPAR $\gamma$ expression is increased in the liver of obese patients and animals (13-15). Thus, PPAR $\gamma$ may enhance hepatic steatosis under conditions of obesity.

Cyclooxygenase (COX), which exists in two isoforms, COX-1 and COX-2, plays an important role in the production of eicosanoids (16). COX-1 is expressed abundantly in many 
tissues. However, COX-2 is not usually expressed in the resting state. Following exposure to a stimulus such as inflammation, the expression of COX-2 increases (17-19). A recent study showed that development of NAFLD in rats with diet-induced obesity was suppressed by concomitant treatment with a COX-2 selective inhibitor (20). However, the mechanisms by which the COX-2 selective inhibitor suppressed NAFLD were not fully explained.

In the present study, we aimed to elucidate the detailed mechanisms through which nimesulide, a COX-2 selective inhibitor, suppresses the development of NAFLD in a murine model of high fat diet (HFD)-induced obesity.

\section{Materials and methods}

Animals. Male C57BL/6J mice (WT mice, 8 weeks old) were purchased from CLEA Japan (Osaka, Japan). All animals were housed in the Center for Laboratory Animal Care of Tottori University School of Medicine (Yonago, Japan). All experimental procedures were performed in accordance with Tottori University Animal Care Guidelines, which conform to the NIH Guide for the Care and Use of Laboratory Animals (NIH publication no. 85-23, revised in 1985). Experimental protocols were approved by the Institutional Animal Care and Use Committee of Faculty of Medicine of Tottori University.

The mice were randomly assigned to three groups (6 mice/ group) and fed either a normal chow diet (NC), a 32\% HFD (CLEA Japan) or a HFD plus nimesulide [HFD-nime; $66 \mathrm{mg} / \mathrm{kg} /$ day: nimesulide was premixed into the $32 \%$ HFD (Cayman Chemical Co., Ann Arbor, MI, USA)] ad libitum for 12 weeks. The concentration of nimesulide mixed with powdery chow was calculated by measuring the food consumption, which was monitored daily. Then, after a $12 \mathrm{~h}$ fast, the animals were sacrificed by pentobarbital anesthesia injection, and blood samples and the livers of these animals were collected.

Oil Red $O$ staining. The liver was isolated, embedded in Tissue-Tek 4583 Optimal Cutting Temperature compound (Sakura Finetek Japan Co., Ltd., Tokyo, Japan) and snap-frozen in liquid nitrogen. Cryostat sections of mouse liver were washed in water for 5 min and then stained with Oil Red O solution (Polysciences, Inc., Warrington, PA, USA) for $30 \mathrm{~min}$. Subsequently, the sections were counterstained with hematoxylin (Muto Pure Chemicals Co., Ltd., Tokyo, Japan) for $1 \mathrm{~min}$.

Measurement of areas of hepatic fibrosis using Sirius red stain. Formalin-fixed, paraffin-embedded liver sections (4- $\mu \mathrm{m}$ thick) were stained with picrosirius red (Sirius red) and counterstained with fast green (both from Chroma-Gesellschaft Schmid GmbH \& Co., Münster, Germany). The areas of hepatic fibrosis were subsequently measured in 10 randomly selected fields in each specimen (magnification, $\mathrm{x} 400$; Olympus BX51N-34 microscope; Olympus Corp., Tokyo, Japan) using WinROOF software (version 5.71; Mitani Corporation, Tokyo, Japan).

Analysis of inflammatory cell infiltration in liver tissue. The mature mouse cell surface glycoprotein F4/80, which is expressed at high levels on Kupffer cells, was immunohistochemically stained using a rat monoclonal anti-F4/80 mouse antibody (cat. no. ab6640; Abcam, Tokyo, Japan) diluted at 1:100 with $0.01 \mathrm{M} / 1$ phosphate-buffered saline (PBS), according to the manufacturer's instructions. Goat anti-rat secondary antibody, from the Histofine Simple Stain Mouse MAX-PO (Rat) kit (cat. no. 414311F; Nichirei Bioscience Inc., Tokyo, Japan) was used without dilution. The immunopositive cells were analyzed in 10 intralobular ocular fields (magnification, $\mathrm{x} 400$; Olympus BX51N-34 microscope) in each specimen.

Biochemical analysis. Blood samples were collected in microtainer tubes (BD Biosciences, Tokyo, Japan) and centrifuged $(9,000 \times \mathrm{g}, 10 \mathrm{~min})$ in order to obtain plasma. Plasma levels of glutamic pyruvic transaminase (GPT)/alanine transaminase (ALT) and glutamic oxaloacetic transaminase (GOT)/aspartate transaminase (AST) were measured using DRI-CHEM 7000 Z (Fujifilm, Tokyo, Japan). The hepatic TG content was determined using a commercially available TG quantification kit (BioVision Inc., Mountain View, CA, USA) and a microtiter plate reader (Sunrise rainbow RC-R; TECAN, Kawasaki, Japan).

$R N A$ extraction and reverse transcription-quantitative polymerase chain reaction $(R T-q P C R)$. The hepatic tissue samples were homogenized and total RNA was extracted using the RNeasy Lipid Tissue Mini kit (Qiagen, Hilden, Germany). The RNA concentrations were determined by measuring the absorbance at $260 \mathrm{~nm}$ using a NanoDrop 1000 spectrophotometer (Thermo Fisher Scientific, Waltham, MA, USA), and the quality of RNA was confirmed by electrophoresis using ethidium bromide-stained $1 \%$ agarose gels. Total RNA $(2 \mu \mathrm{g})$ was reverse transcribed in a final volume of $11.5 \mu \mathrm{l}$ containing $4 \mu \mathrm{l} 5 \mathrm{X}$ standard buffer, $2 \mu \mathrm{l} 0.1 \mathrm{M}$ dithiothreitol, $1 \mu \mathrm{l}$ SuperScript II RNase H-reverse transcriptase (Invitrogen Life Technologies, Carlsbad, CA, USA), $2 \mu 110$ M MdNTP (Promega, Madison, WI, USA), $1 \mu 150 \mathrm{pmol} / \mu 1$ Random Primer (Promega), $0.5 \mu 1100 \mathrm{pmol} / \mu \mathrm{l}$ Oligo (dt)15 Primer (Promega) and $1 \mu \mathrm{l} 40 \mathrm{U} / \mu 1$ ribonuclease inhibitor (Wako Pure Chemical Industries, Ltd., Osaka, Japan). The mixtures were incubated at $37^{\circ} \mathrm{C}$ for $60 \mathrm{~min}, 95^{\circ} \mathrm{C}$ for $5 \mathrm{~min}$ and then cooled to $4^{\circ} \mathrm{C}$ for 5 min using a MyCycler Thermal Cycler (Bio-Rad Laboratories, Inc., Hercules, CA, USA).

Quantitative PCR assays (7900HT Fast Real-Time PCR system; Applied Biosystems, Carlsbad, CA, USA) were performed in a final volume of $10 \mathrm{ml}$ containing 250 nM Universal ProbeLibrary probe (Roche, Basel, Switzerland), $900 \mathrm{nM}$ forward primer, $900 \mathrm{nM}$ reverse primer, $5 \mathrm{ml}$ EXPRESS qPCR Supermix with Premixed Rox (Invitrogen) and $2 \mathrm{ml}$ cDNA. The mRNA levels of COX-1 (GenBank: NM_008969), COX-2 (GenBank: NM_011198), PPAR $\gamma$ (mouse) (GenBank: NM_011146), PPAR $\gamma$ (human) (GenBank: NM_015869), tissue inhibitor of metalloproteinases-1 (TIMP-1; GenBank: NM_011593), procollagen-1 (GenBank: U08020), transforming growth factor- $\beta 1$ (TGF- $\beta 1$; GenBank: NM_011577) and monocyte chemoattractant protein-1 (MCP-1; GenBank: NM_100127112) were assessed using the $7900 \mathrm{HT}$ Fast Real-Time PCR system with SDS2.3 software (Applied Biosystems). Human $\beta$-actin (GenBank: NM_001101) and mouse $\beta$-actin (GenBank: NM_007393) were used as internal controls for RNA integrity. The PCR products were eluted into ultra pure water using a QIAquick gel extraction kit (Qiagen), and 
a standard curve was prepared using serial dilutions. The following thermal cycle conditions were used: $95^{\circ} \mathrm{C}$ for $20 \mathrm{sec}$ followed by 45 cycles of $1 \mathrm{sec}$ at $95^{\circ} \mathrm{C}$ and $20 \mathrm{sec}$ at $60^{\circ} \mathrm{C}$. The relative mRNA expression levels were calculated using the $2^{-\Delta \Delta C T}$ method.

Measurement of hepatic 15-deoxy- $\Delta^{12,14}$-prostaglandin $J_{2}$ $\left(15 d-P G J_{2}\right)$. The hepatic content of $15 \mathrm{~d}-\mathrm{PGJ}_{2}$ was quantified using a commercially available enzyme-linked immunosorbent assay (Enzo Life Sciences, Tokyo, Japan) in accordance with the manufacturer's instructions.

Cell culture and 15d-PGJ $J_{2}$ treatment. Human hepatocarcinoma HepG2 cells (a gift from Professor Shiota, Division of Molecular and Genetic Medicine, Tottori University, Yonago, Japan) were seeded $\left(30,000\right.$ cells $\left./ \mathrm{cm}^{2}\right)$ and maintained for $24 \mathrm{~h}$ in DMEM (Wako Pure Chemical Industries, Ltd.) supplemented with $2 \mathrm{mM}$ glutamine, $1 \%$ penicillin/streptomycin solution and $10 \% \mathrm{FBS}$, at $37^{\circ} \mathrm{C}$ in a $5 \% \mathrm{CO}_{2}$ humidified atmosphere. The compound $15 \mathrm{~d}-\mathrm{PGJ}_{2}$ was then added at a concentration of 5 or 10 $\mu \mathrm{M}$ and the cells were incubated for a further $48 \mathrm{~h}$. The solvent DMSO was used as a vehicle control. RNA was extracted using an RNeasy mini kit, and the expression of $\beta$-actin and PPAR $\gamma$ was quantified using the real-time RT-PCR system.

Intraperitoneal glucose tolerance test (ipGTT) and plasma insulin measurement. To assess glucose tolerance after 12 weeks, the mice were injected with glucose $(1 \mathrm{mg} / \mathrm{g}$ body weight) intraperitoneally after a 12-h fast. Blood samples were drawn from the tail vein at baseline and at 15, 30, 60, 90 and $120 \mathrm{~min}$ after the injection. The blood glucose level was measured using an automatic blood glucose meter (Glucose Pilot; Iwai Chemicals Ltd., Tokyo, Japan). Plasma insulin levels was measured using a Mercodia mouse insulin EIA kit (Mercodia Inc., Winston-Salem, NC, USA).

Statistical analysis. Data were processed using StatView J-4.5 software (SAS Institute Inc., Cary, NC, USA). Values are expressed as the means \pm standard error of mean (SEM). Values of groups were analyzed by one-way ANOVA with post-hoc tests for multiple comparisons. Perfusion recovery among groups was assessed using ANOVA with repeated measures. The Student's t-test was used for comparisons between two groups. $\mathrm{P}<0.05$ was considered to indicate a statistically significant difference.

\section{Results}

Animal model of obesity and NAFLD. As shown in Fig. 1, the body weights of the mice in the HFD group significantly increased compared with those in the NC group. Histopathologically, Oil Red O-positive areas, which indicated TG accumulation in the liver, were clearly larger in the HFD group (Fig. 1B). COX-2 mRNA expression in the liver was significantly increased in the HFD group compared with the NC group, although no difference was observed in COX-1 mRNA expression between the two groups (Fig. 1C and D).

Effect of the COX-2 selective inhibitor on body weight and NAFLD. The body weights of mice in the HFD-nime group increased and were comparable with those in the HFD group (Fig. 1E). Histopathological findings indicated that TG accumulation was suppressed in the HFD-nime group compared with that in the HFD group (Fig. 1F). Similarly, the increased hepatic TG content observed in the HFD group was also significantly suppressed by nimesulide (Fig. 2A). Plasma GPT levels in the HFD group were significantly increased compared with those in the NC group. Nimesulide significantly suppressed the increase of plasma GPT in the HFD group (Fig. 2B). Plasma GOT levels exhibited a similar tendency although they did not reach a statistically significant level (Fig. 2C).

Hepatic PPAR $\gamma$ mRNA expression and $5 d-P G J_{2}$ content. PPAR $\gamma$ mRNA expression in the liver was significantly increased in the HFD group whereas nimesulide significantly suppressed PPAR $\gamma$ mRNA expression in the HFD-nime group (Fig. 2D). The findings of previous studies suggested that the mRNA expression and activation of PPAR $\gamma$ were regulated by $15 \mathrm{~d}-\mathrm{PGJ}_{2}$, which is one of the metabolites of COX-2 and a PPAR $\gamma$ natural agonist, in various types of cell $(21,22)$. Therefore, we examined whether $15 \mathrm{~d}-\mathrm{PGJ}_{2}$ was increased in the livers of obese mice, and whether it was suppressed by nimesulide, using an enzyme-linked immunosorbent assay. As shown in Fig. 2E, the hepatic $15 \mathrm{~d}-\mathrm{PGJ}_{2}$ content was higher in the HFD group than in the NC group, and nimesulide completely suppressed $15 \mathrm{~d}-\mathrm{PGJ}_{2}$ content in the liver. In order-to determine whether $15 \mathrm{~d}_{-} \mathrm{PGJ}_{2}$ enhanced the expression of PPAR $\gamma$ at the mRNA and protein level, we performed in vitro experiments using human hepatocarcinoma HepG2 cells. As shown in Fig. 2F, 15d-PGJ enhanced the mRNA expression of PPAR $\gamma$ in HepG2 cells in a dose-dependent manner and $10 \mu \mathrm{M} 15 \mathrm{~d}_{-} \mathrm{PGJ}_{2}$ significantly increased the mRNA expression of PPAR $\gamma$.

Effect of the COX-2 selective inhibitor on glucose metabolism in obese mice. Previous studies have suggested that NAFLD is a risk factor for disordered glucose metabolism (1-3). Therefore, in order to determine whether nimesulide is capable of reversing disordered glucose metabolism, we performed an ipGTT. The mice in the HFD group showed impaired glucose tolerance, but this was significantly ameliorated by the administration of nimesulide (Fig. 3A). In addition, the mice in the HFD group developed hyperinsulinemia, which was also suppressed by nimesulide (Fig. 3B).

Effects of $C O X-2$ on hepatic fibrosis. There was no significant difference in the extent of the area immunostained with Sirius red between the NC group and the HFD group. Furthermore, the administration of nimesulide did not significantly affect the area of Sirius red immunostaining (Fig. 4A and C). The mRNA expression of TIMP-1 and procollagen-1 in the liver were significantly increased in the HFD group compared with the NC group (Fig. 5A and B). Nimesulide significantly suppressed the mRNA expression of TIMP-1 and procollagen-1 in the HFD-nime group (Fig. 5A and B). However, nimesulide did not alter the mRNA expression of TGF- $\beta 1$ (Fig. 5C).

Effect of COX-2 on inflammatory reactions in the liver. The number of F4/80-positive Kupffer cells was significantly increased in the HFD group (Fig. 4B and D). Nimesulide significantly suppressed the number of F4/80-positive cells in 
A

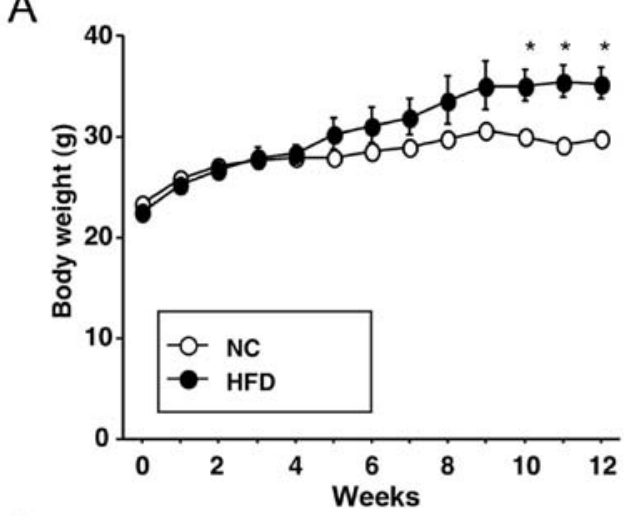

C
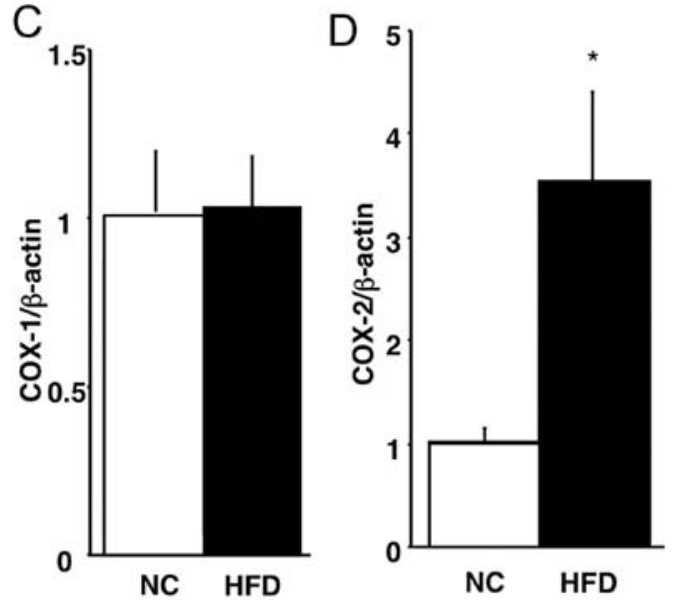

$\mathrm{F}$
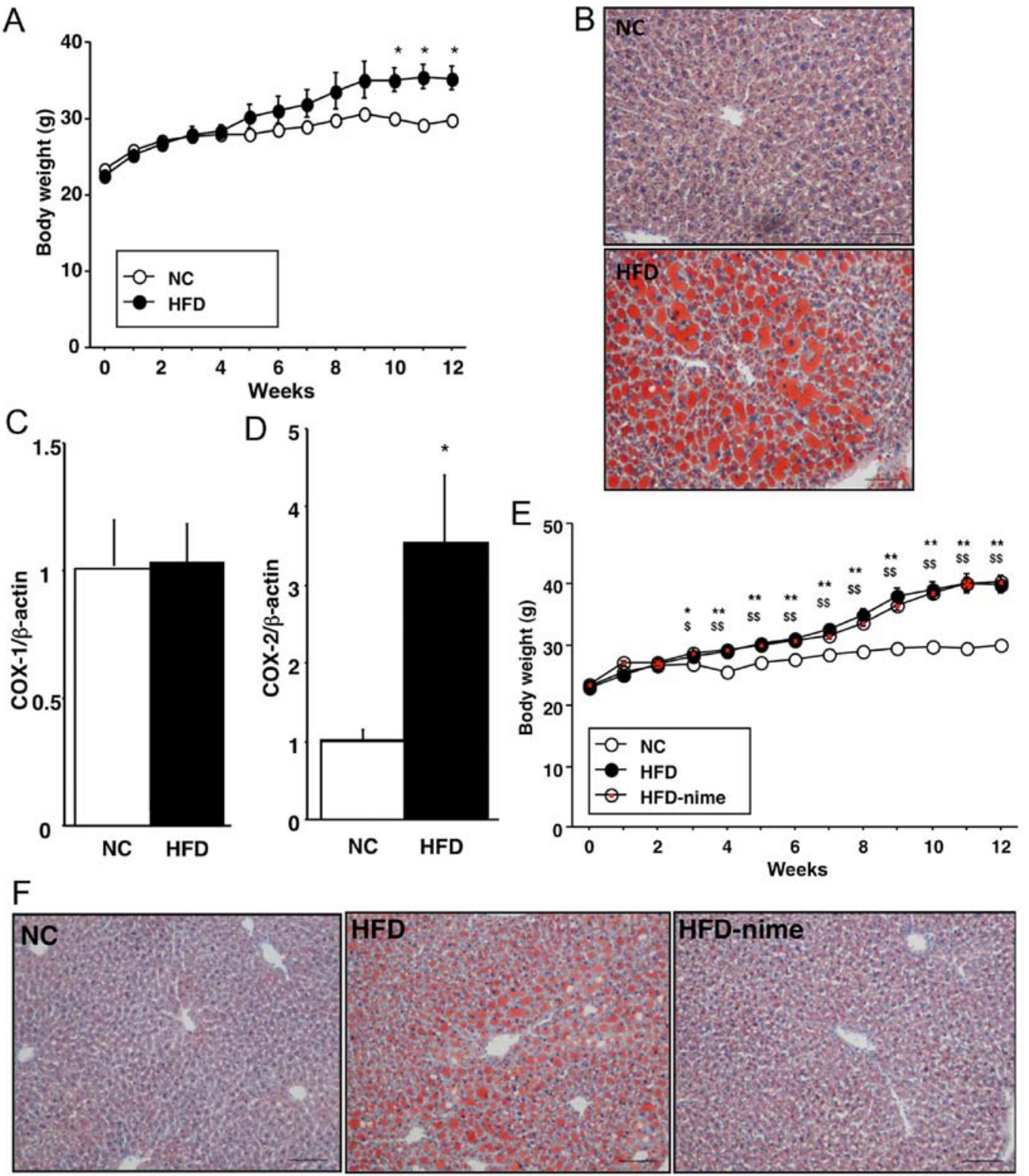

Figure 1. (A) Weekly body weight measurements of the mice in the NC and HFD groups ( $\mathrm{n}=3$ per group). (B) Oil Red $\mathrm{O}$ staining of the liver in the NC and HFD groups (original magnification, $x 100$ ). (C and D) Cyclooxygenase (COX)-1 and -2 mRNA expression in the livers of mice in the NC and HFD groups ( $\mathrm{n}=9$ per group. ${ }^{*} \mathrm{P}<0.05$ vs. NC. (E) Weekly body weight measurements of the mice in the NC, HFD and HFD-nime groups ( $\mathrm{n}=6$ per group). ${ }^{*} \mathrm{P}<0.05 \mathrm{HFD}$ vs. NC, ${ }^{* *} \mathrm{P}<0.01$ HFD vs. NC, ${ }^{\$} \mathrm{P}<0.05$ HFD-nime vs. NC, ${ }^{\$ \$} \mathrm{P}<0.01$ HFD-nime vs. NC. (F) Oil Red O staining of the liver in the NC, HFD and HFD-nime groups (original magnification, $\mathrm{x} 100$ ). NC, normal chow diet; HFD, high fat diet; HFD-nime, high fat plus nimesulide.

the HFD-nime group (Fig. 4B and D). Similarly, the mRNA expression of MCP-1 in the liver was significantly increased in the HFD group and significantly suppressed by nimesulide in the HFD-nime group (Fig. 5D).

\section{Discussion}

A previous study showed that COX-2 selective inhibitors suppressed hepatic steatosis in rats with HFD-induced obesity (20). However, the detailed mechanism responsible for this effect was not elucidated. PPAR $\gamma$, which belongs to the PPAR family of nuclear receptors, is mainly expressed in adipose tissue and it plays an important role in lipid metabolism (10). In previous studies, PPAR $\gamma$ expression was found to be increased in the liver of obese rats and to be involved in the development of NAFLD (13-15,23,24). In the present study, we confirmed that the mRNA expression of PPAR $\gamma$ was increased in the livers of mice with HFD-induced obesity, and that it was suppressed by nimesulide (Fig. 2D). The histopathological examination of mouse liver tissues showed that nimesulide suppressed hepatic steatosis (Fig. 1F). These results suggest that the COX-2 selective inhibitor suppressed hepatic steatosis by suppressing the expression and activation of PPAR $\gamma$.

$15 \mathrm{~d}-\mathrm{PGJ}_{2}$ is a prostanoid derived from prostaglandin $\mathrm{D}_{2}$ and it is a natural PPAR $\gamma$ agonist (25). In the current study, we showed that the $15 \mathrm{~d}-\mathrm{PGJ}_{2}$ concentration was increased in the livers of mice with HFD-induced obesity. The results of our in vitro experiment as well as those of a previous study revealed that $15 \mathrm{~d}-\mathrm{PGJ}_{2}$ increased not only PPAR $\gamma$ activity but also its expression in hepatocytes (26). PPAR $\gamma$ increases 

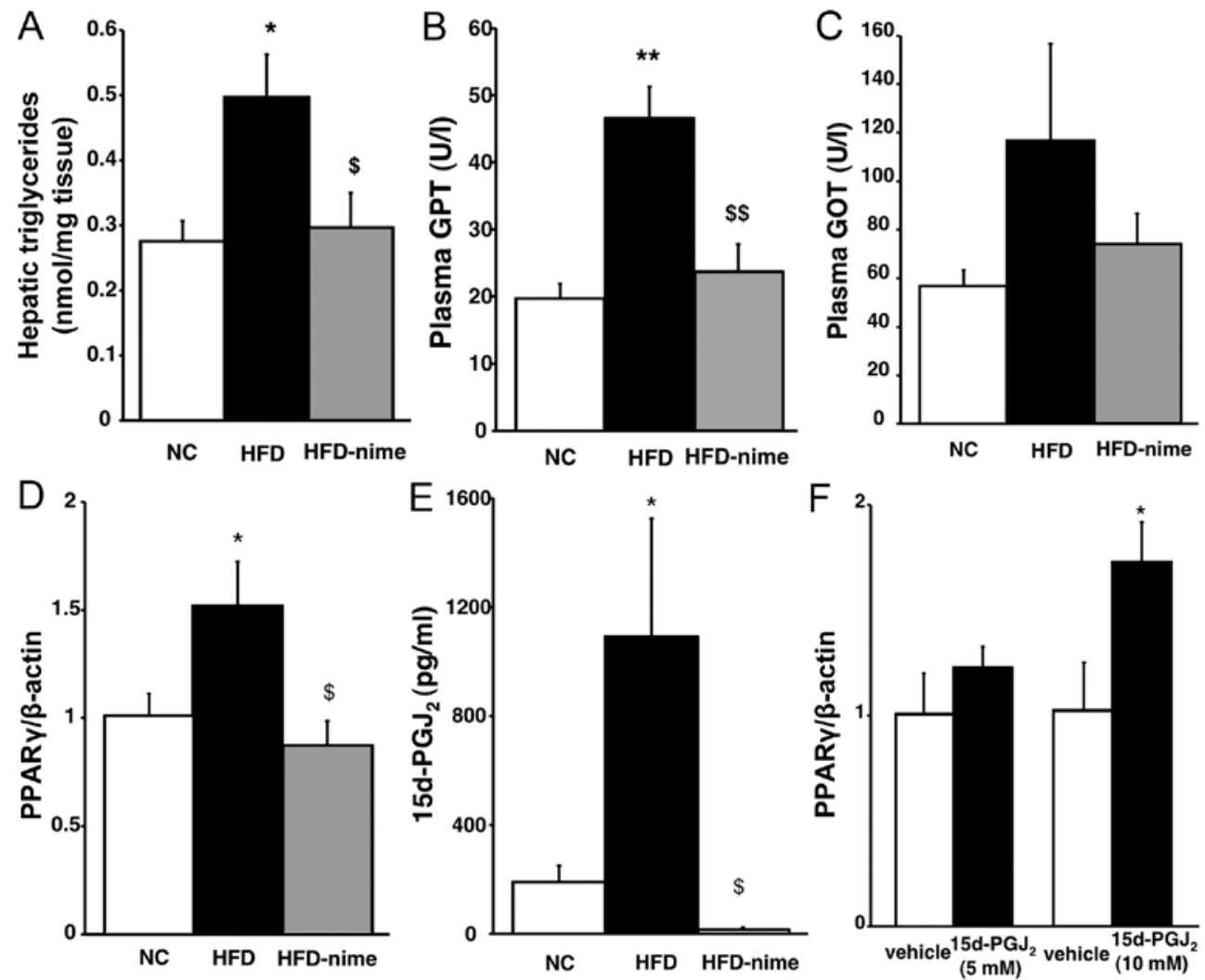

Figure 2. (A) Triglyceride content in the livers of mice in the three groups ( $\mathrm{n}=5$ per group). (B and C) Plasma levels of GPT and GOT in the three groups ( $\mathrm{n}=6$ per group). ${ }^{*} \mathrm{P}<0.05$ vs. NC, ${ }^{* *} \mathrm{P}<0.01$ vs. NC, ${ }^{\$} \mathrm{P}<0.05$ vs. HFD, ${ }^{\$ S} \mathrm{P}<0.01$ vs. HFD. (D) PPAR $\gamma$ mRNA expression in the livers of mice in the NC, HFD and HFD-nime groups ( $\mathrm{n}=6$ per group). (E) $15 \mathrm{~d}-\mathrm{PGJ} \mathrm{J}_{2}$ content in the liver of mice in the three groups ( $\mathrm{n}=6$ per group). ${ }^{*} \mathrm{P}<0.05 \mathrm{vs}$. NC, ${ }^{S} \mathrm{P}<0.01 \mathrm{vs}$. $\mathrm{HFD}$. (F) PPAR $\gamma$ mRNA expression at $48 \mathrm{~h}$ after treatment with $15 \mathrm{~d}-\mathrm{PGJ}_{2}$ ( $\mathrm{n}=6$ per group). " $\mathrm{P}<0.05$ vs. vehicle. GPT, Plasma glutamic pyruvic transaminase; GOT, glutamic oxaloacetic transaminase; NC, normal chow diet; HFD, high fat diet; HFD-nime, high fat plus nimesulide; PPAR $\gamma$, peroxisome proliferator-activated receptor $\gamma ; 15$ d-PGJ 2,15 -deoxy- $\Delta^{12,14}$-prostaglandin $\mathrm{J}_{2}$.
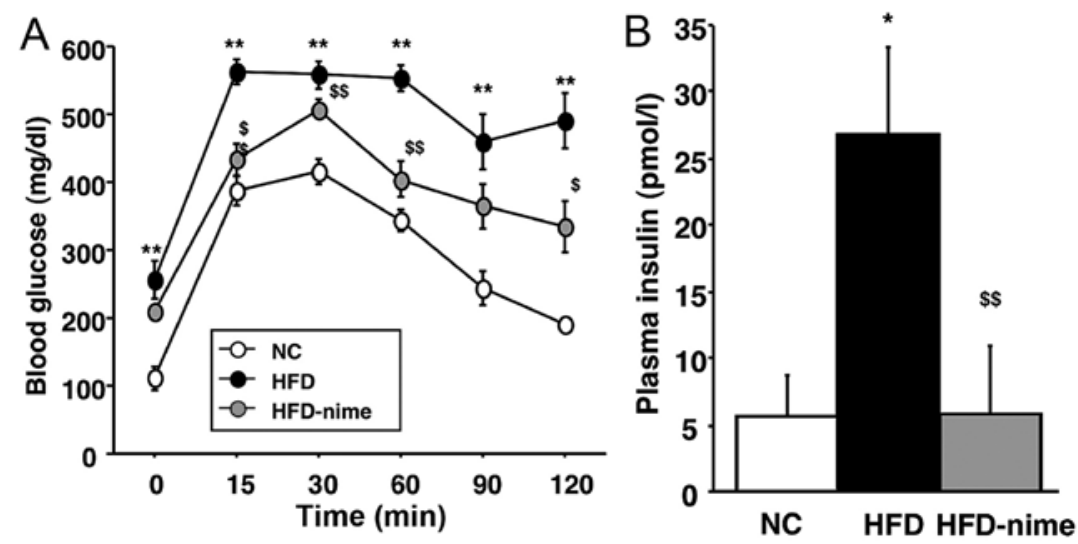

Figure 3. (A) Measurement of blood glucose by the ipGTT. Blood glucose was measured prior to glucose injection and at 15, 30, 60, 90, 120 min thereafter. ( $\mathrm{n}=6$ per group). (B) Fasting blood insulin concentration in the NC, HFD and HFD-nime groups ( $\mathrm{n}=5,6,6$, respectively). ${ }^{*} \mathrm{P}<0.05$ vs. NC, ${ }^{* *} \mathrm{P}<0.01$ vs. NC, ${ }^{\$} \mathrm{P}<0.05$ vs. HFD, ${ }^{\$ \$} \mathrm{P}<0.01$ vs. HFD. ipGTT, intraperitoneal glucose tolerance test; NC, normal chow diet; HFD, high fat diet; HFD-nime, high fat plus nimesulide.

lipogenic gene expression, such as fatty acid synthase and sterol regulatory element-binding protein-1, as evidenced by increased levels of a lipogenic gene, and induces lipid accumulation $(23,27,28)$. Moreover, hepatocyte-specific PPAR $\gamma$-deficient mice showed decreased lipogenic gene expression, and did not accumulate fat in the liver despite consuming an HFD (29). As a result, it was hypothesized that
$15 \mathrm{~d}-\mathrm{PGJ}_{2}$ stimulates the expression and activation of PPAR $\gamma$ in the livers of mice with HFD-induced obesity, and that NAFLD development is mediated by the increased expression of this lipogenic gene. However, in clinical cases, TZDs, which are well-known PPAR $\gamma$ activators, are often used to treat NAFLD and diabetes mellitus $(11,12)$. It remains unclear whether TZDs ameliorate hepatic steatosis as a consequence of their primary 


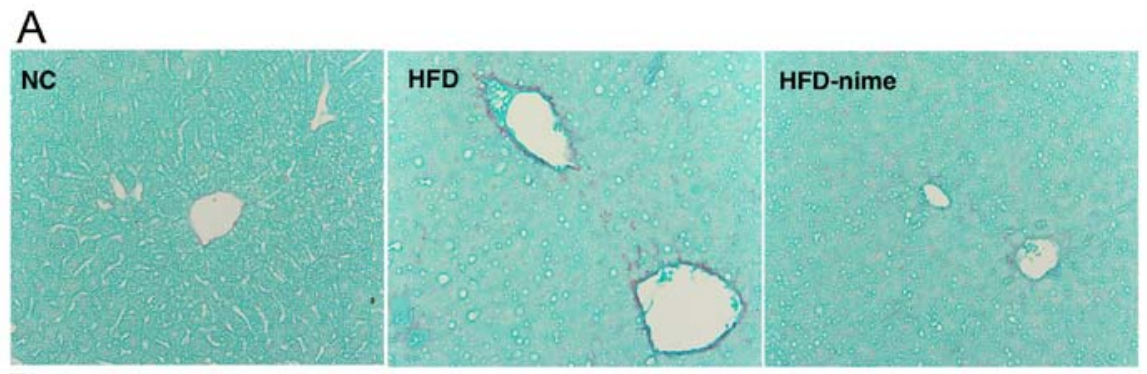

B
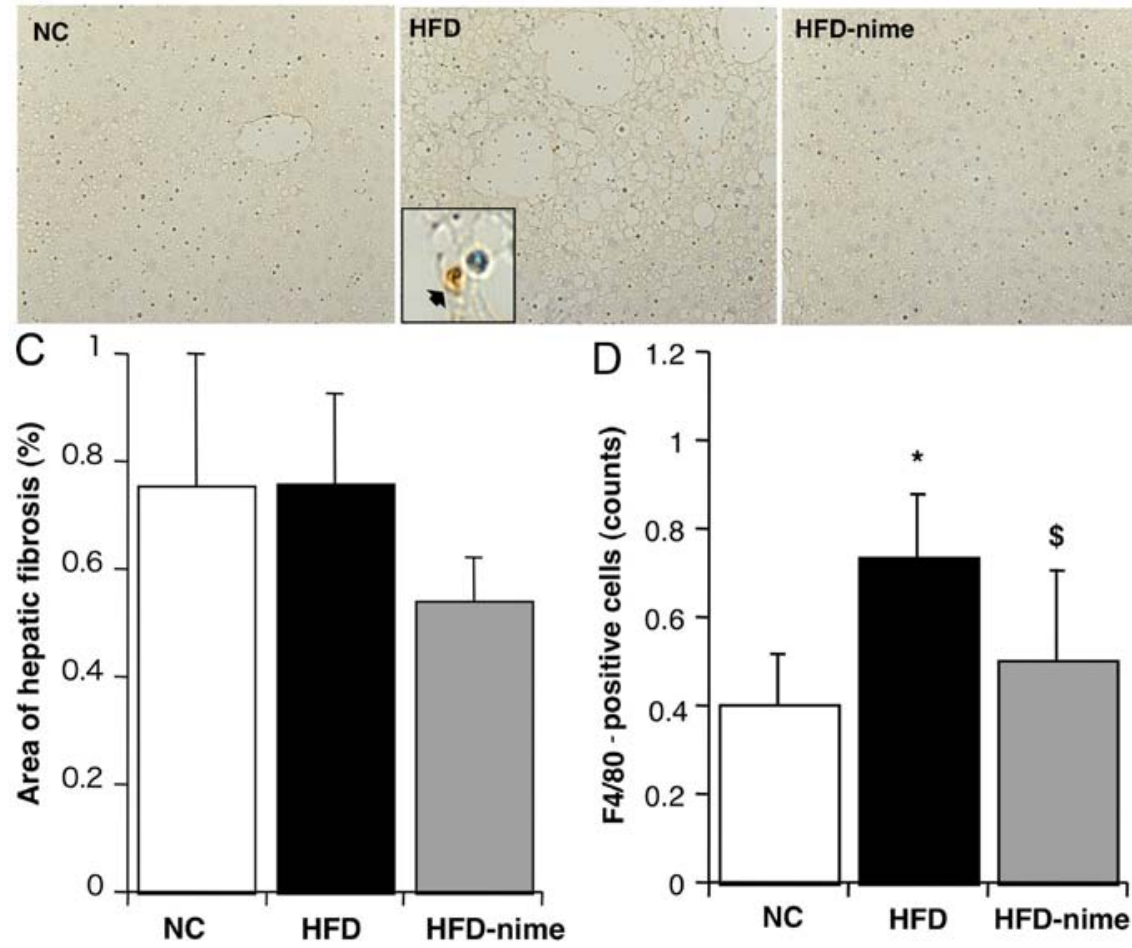

Figure 4. (A and C) Areas of hepatic fibrosis determined by Sirius red immunostaining. Areas of Sirius red immunostaining (original magnification, $\mathrm{x} 400$ ) measured using image analysis ( $\mathrm{n}=6,6,8$, respectively). Areas of hepatic fibrosis did not change among the groups. (B) F4/80 immunostaining for Kupffer cells (original magnification, $\mathrm{x} 400$, and within the box, high maginification $\mathrm{x} 1,000$, immunopositive-F4/80 cell denoted by black arrow). (D) Numbers of immunopositive-F4/80 cells in each group ( $\mathrm{n}=6,6,8$, respectively). "P<0.05 vs. NC, ${ }^{\$} \mathrm{P}<0.05$, vs. HFD. NC, normal chow diet; HFD, high fat diet; HFD-nime, high fat plus nimesulide.
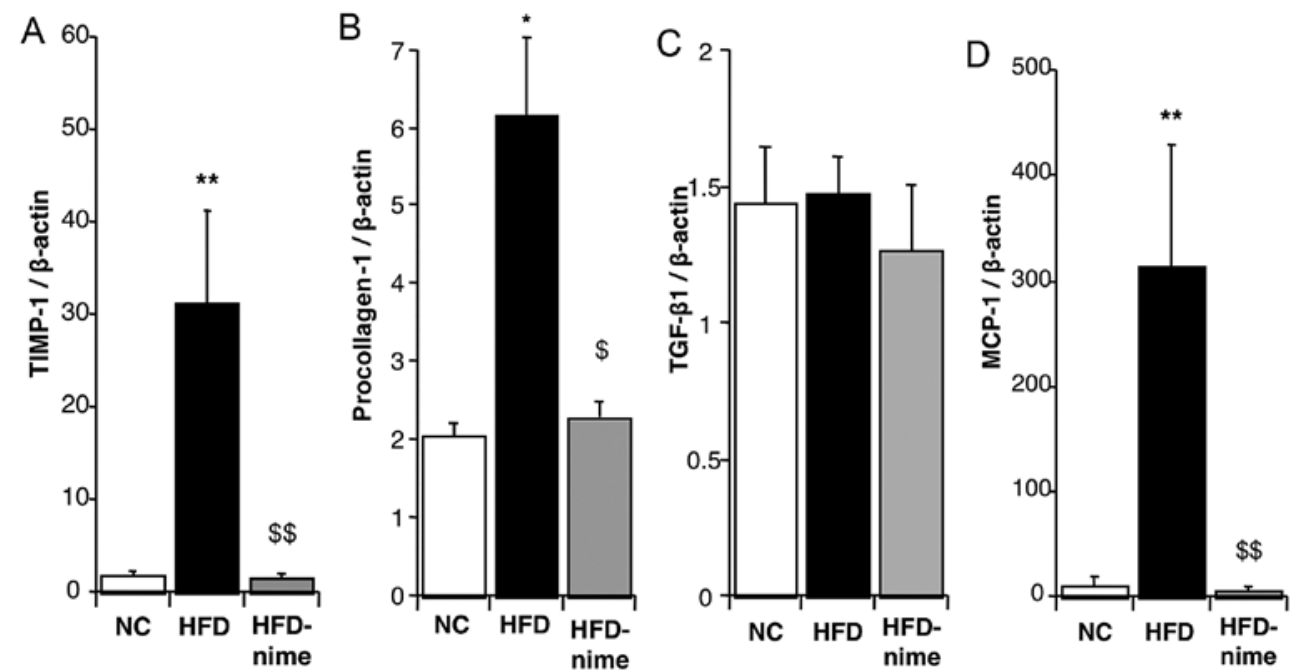

Figure 5. (A) TIMP-1 mRNA expression in the liver of mice in the NC, HFD and HFD-nime groups ( $\mathrm{n}=3,6,8$, respectively). (B) Procollagen-1 mRNA expression in the liver of mice in the NC, HFD and HFD-nime groups ( $\mathrm{n}=3,68$, respectively). (C) TGF- $\beta 1$ mRNA expression in the liver of mice in the NC, HFD and HFD-nime groups ( $\mathrm{n}=3,6,8$, respectively). (D) MCP-1 mRNA expression in the liver of mice in the NC, HFD and HFD-nime groups ( $\mathrm{n}=3,6,8$, respectively). ${ }^{*} \mathrm{P}<0.05$ vs. NC, ${ }^{* *} \mathrm{P}<0.01$ vs. NC, ${ }^{\$} \mathrm{P}<0.05$ vs. HFD, ${ }^{\$ \$} \mathrm{P}<0.01$ vs. HFD. TIMP-1, tissue inhibitor of metalloproteinases-1; NC, normal chow diet; HFD, high fat diet; HFD-nime, high fat plus nimesulide, TGF- $\beta 1$, transforming growth factor- $\beta 1$; MCP-1, monocyte chemoattractant protein-1. 
insulin-sensitizing effects on adipose tissue (12). However, the following findings of previous studies suggest that the beneficial effects of TZDs on NAFLD and insulin resistance were induced by the activation of PPAR $\gamma$ in the adipose tissue, rather than in the liver or striated muscle. Transgenic mice characterized by adipocyte-specific PPAR $\gamma$ activation showed reduced insulin resistance, similar to that observed in a model of mice with HFD-induced obesity treated with TZDs. Muscle-specific PPAR $\gamma$-deficient mice showed improved free fatty acid metabolism and insulin resistance under treatment with TDZs (30-32). In addition, in liver-specific PPAR $\gamma$ deficient mice, the development of HFD-induced NAFLD and insulin resistance was suppressed (29). Therefore, we suggest that the presence of PPAR $\gamma$ in adipose tissue is important in the treatment of NAFLD and insulin resistance, and that PPAR $\gamma$ in the liver plays a crucial role in the development of NAFLD in mice with HFD-induced obesity.

It is well-known that insulin regulates gluconeogenesis and glycogen synthesis in the liver to maintain the blood glucose levels $(6,33)$. Previous studies suggested that the excessive accumulation of TGs or FFAs in the liver suppressed the metabolic pathway of glucose by activating protein kinase $\mathrm{C} \varepsilon(\mathrm{PKC} \varepsilon)(34,35)$, thereby leading to hepatic insulin resistance and disorders of glucose metabolism. In addition, ezetimibe, which is known to prevent TG accumulation, suppresses the development of NAFLD in the livers of obese Zucker rats $(36,37)$. Thus, the inhibition of fat accumulation in the liver reduces hepatic insulin resistance. In this study, the HFD group showed impaired glucose metabolism and this was ameliorated in the HFD-nime group (Fig. 3). Consequently, nimesulide may reverse hepatic insulin resistance by suppressing the development of NAFLD. In addition, a study showed that prostaglandin $\mathrm{E}_{2}\left(\mathrm{PGE}_{2}\right)$, which is one of the main products of COX-2, also induced hepatic insulin resistance via its receptor EP3 $\beta$ (38). Thus, the increased expression of COX-2 in the livers of obese mice may be one of the main contributors to excessive NAFLD and hepatic insulin resistance.

In the present study, it was found that nimesulide attenuated hepatic inflammation as another factor involved in the second hit of the progress of NAFLD. Nimesulide reduced the number of Kupffer cells infiltrating the liver and decreased the gene expression of MCP-1, which directs trafficking of immune cell to sites of tissue damage. The products of lipid peroxidation can mediate inflammatory recruitment by activating $\mathrm{NF}-\kappa \mathrm{B}$ and COX-2 (39). The activation of NF- $\mathrm{KB}$ was accompanied by the increased hepatic expression of several inflammatory cytokines [interleukin (IL)-1 $\beta$, TNF- $\alpha$ and IL-6] and by an increase in plasma MCP-1 levels, all known to be NF- $\mathrm{BB}$-dependent inflammatory cytokines (40). Kupffer cells are crucial for the early development of NASH by promoting blood monocyte infiltration through the production of interferon $\gamma$-induced protein-10 and MCP-1 (41). MCP-1 gene expression and the number of Kupffer cells infiltrating the liver were reduced by nimesulide and thereby regulated inflammation.

In the present study, we examined whether nimesulide attenuated the progression of liver fibrosis. As a HFD did not induce immunohistological liver fibrosis, the effect of nimesulide on liver fibrosis could not be examined. However, the increased hepatic gene expression of TIMP-1 and procollagen-1 in the HFD group were suppressed by nimesulide.
These findings suggest that nimesulide may attenuate hepatic fibrogenesis in NAFLD.

Notably, the body weights of the mice in the HFD-nime group were comparable with those in the HFD group whereas hepatic TG contents were decreased by nimesulide administration almost to the control level. It has been previously reported that in rats fed a HFD in combination with celecoxib (COX-2 selective inhibitor), TG accumulation in the liver was attenuated, without affecting body weight (20). Thus, these findings taken together with the results of the present study, suggest that the reduction of hepatic TG content by nimesulide does not affect body weight. However, further experiments are necessary to examine this possibility in more detail.

This study has some limitations. Firstly, a clear, casual association between the decrease in hepatic $15 \mathrm{~d}-\mathrm{PGJ}_{2}$ content and histological amelioration of NAFLD by pre-treatment with nimesulide in vivo was not shown, although it was demonstrated that $15 \mathrm{~d}-\mathrm{PGJ}_{2}$ induced PPAR $\gamma$ expression in HepG2 cells. This suggests that other factors may contribute to the histological amelioration obtained with nimesulide. Secondly, it has been shown that the upregulation of COX-2 in adipocytes increases the production of inflammatory $\mathrm{PGE}_{2}$, leading to insulin resistance (20). However, the effects of nimesulide on adipose tissue were not examined in the present study. Examining the effects of nimesulide on $15 \mathrm{~d}-\mathrm{PGJ}_{2}$ in adipose tissue would further clarify the amelioration observed in this murine model of NAFLD. Thirdly, the reduction in insulin resistance induced by nimesulide may also be attributed to the ability of nimesulide to restore hepatic TG accumulation. Further experiments concerning hepatic glucose output or hepatic insulin receptor substrate phosphorylation are necessary for confirmation. Fourthly, our study provided no information that would confirm whether hepatocytic COX-2 and $15 \mathrm{~d}-\mathrm{PGJ}_{2}$ are upregulated in steatohepatitis and successfully blocked by nimesulide, which is a clear limitation. Finally, information to validate the functions of PPAR $\gamma$ on hepatocytes is lacking in the present study as the expression of lipogenesis/lipid oxidation genes was not evaluated in vivo or in vitro and the production of reactive oxygen species was not examined in hepatocytes.

In conclusion, we suggest that $\mathrm{COX}-2$ expression in the livers of mice with HFD-induced obesity is involved in the development of NAFLD through the $15 \mathrm{~d}-\mathrm{PGJ}_{2}-\mathrm{PPAR} \gamma$ pathway. The inhibition of COX-2 by nimesulide suppressed hepatic inflammation and fibrogenesis, and reduced insulin resistance in NAFLD. Nimesulide may contribute to the treatment of NAFLD and metabolic syndrome. Thus, COX-2 may emerge as a molecular target for preventing the development of NAFLD and insulin resistance in diet-related obesity.

\section{References}

1. Angulo P: Nonalcoholic fatty liver disease. N Engl J Med 346: 1221-1231, 2002.

2. Pagano G, Pacini G, Musso G, Gambino R, Mecca F, Depetris N, Cassader M, David E, Cavallo-Perin P and Rizzetto M: Nonalcoholic steatohepatitis, insulin resistance, and metabolic syndrome: further evidence for an etiologic association. Hepatology 35: 367-372, 2002.

3. Petersen KF, Dufour S, Befroy D, Lehrke M, Hendler RE and Shulman GI: Reversal of nonalcoholic hepatic steatosis, hepatic insulin resistance, and hyperglycemia by moderate weight reduction in patients with type 2 diabetes. Diabetes 54: 603-608, 2005. 
4. Scorletti E, Calder PC and Byrne CD: Non-alcoholic fatty liver disease and cardiovascular risk: metabolic aspects and novel treatments. Endocrine 40: 332-343, 2011.

5. Angrand PO, Coffinier C and Weiss MC: Response of the phosphoenolpyruvate carboxykinase gene to glucocorticoids depends on the integrity of the cAMP pathway. Cell Growth Differ 5: 957-966, 1994.

6. Cross DA, Alessi DR, Cohen P, Andjelkovich M and Hemmings BA: Inhibition of glycogen synthase kinase- 3 by insulin mediated by protein kinase B. Nature 378: 785-789, 1995 .

7. Samuel VT, Petersen KF and Shulman GI: Lipid-induced insulin resistance: unravelling the mechanism. Lancet 375: 2267-2277, 2010.

8. Greenberg AS, Coleman RA, Kraemer FB, McManaman JL, Obin MS, Puri V, Yan QW, Miyoshi H and Mashek DG: The role of lipid droplets in metabolic disease in rodents and humans. J Clin Invest 121: 2102-2110, 2011.

9. Evans RM, Barish GD and Wang YX: PPARs and the complex journey to obesity. Nat Med 10: 355-361, 2004.

10. Rosen ED, Hsu CH, Wang X, Sakai S, Freeman MW, Gonzalez FJ and Spiegelman BM: C/EBPalpha induces adipogenesis through PPARgamma: a unified pathway. Genes Dev 16: 22-26, 2002.

11. Ratziu V,GiralP,JacqueminetS, CharlotteF,Hartemann-Heurtier A, Serfaty L, Podevin P, Lacorte JM, Bernhardt C, Bruckert E, et al LIDO Study Group: Rosiglitazone for nonalcoholic steatohepatitis: one-year results of the randomized placebo-controlled Fatty Liver Improvement with Rosiglitazone Therapy (FLIRT) Trial Gastroenterology 135: 100-110, 2008.

12. Ratziu V, Charlotte F, Bernhardt C, Giral P, Halbron M, Lenaour G Hartmann-Heurtier A, Bruckert E and Poynard T; LIDO Study Group: Long-term efficacy of rosiglitazone in nonalcoholic steatohepatitis: results of the fatty liver improvement by rosiglitazone therapy (FLIRT 2) extension trial. Hepatology 51: 445-453, 2010.

13. Pettinelli P and Videla LA: Up-regulation of PPAR-gamma mRNA expression in the liver of obese patients: an additional reinforcing lipogenic mechanism to SREBP-1c induction. J Clin Endocrinol Metab 96: 1424-1430, 2011.

14. Edvardsson U, Ljungberg A and Oscarsson J: Insulin and oleic acid increase PPARgamma2 expression in cultured mouse hepatocytes . Biochem Biophys Res Commun 340: 111-117, 2006.

15. Matsusue K, Kusakabe T, Noguchi T, Takiguchi S, Suzuki T, Yamano S and Gonzalez FJ: Hepatic steatosis in leptin-deficient mice is promoted by the PPARgamma target gene Fsp27. Cell Metab 7: 302-311, 2008

16. Dubois RN, Abramson SB, Crofford L, Gupta RA, Simon LS, Van De Putte LB and Lipsky PE: Cyclooxygenase in biology and disease. FASEB J 12: 1063-1073, 1998.

17. Murakami M, Matsumoto R, Austen KF and Arm JP: Prostaglandin endoperoxide synthase- 1 and -2 couple to different transmembrane stimuli to generate prostaglandin D2 in mouse bone marrow-derived mast cells. J Biol Chem 269: 22269-22275, 1994.

18. Anderson GD, Hauser SD, McGarity KL, Bremer ME, Isakson PC and Gregory SA: Selective inhibition of cyclooxygenase (COX)-2 reverses inflammation and expression of COX-2 and interleukin 6 in rat adjuvant arthritis. J Clin Invest 97 2672-2679, 1996

19. Ricciotti E and FitzGerald GA: Prostaglandins and inflammation. Arterioscler Thromb Vasc Biol 31: 986-1000, 2011.

20. Hsieh PS, Jin JS, Chiang CF, Chan PC, Chen CH and Shih KC: COX-2-mediated inflammation in fat is crucial for obesity-linked insulin resistance and fatty liver. Obesity (Silver Spring) 17: 1150-1157, 2009.

21. Muzio G, Trombetta A, Maggiora M, Martinasso G, Vasiliou V, Lassen N and Canuto RA: Arachidonic acid suppresses growth of human lung tumor A549 cells through down-regulation of ALDH3A1 expression. Free Radic Biol Med 40: 1929-1938, 2006.

22. Avis I, Martínez A, Tauler J, Zudaire E, Mayburd A, Abu-Ghazaleh R, Ondrey F and Mulshine JL: Inhibitors of the arachidonic acid pathway and peroxisome proliferator-activated receptor ligands have superadditive effects on lung cancer growth inhibition. Cancer Res 65: 4181-4190, 2005.

23. Schadinger SE, Bucher NL, Schreiber BM and Farmer SR: PPARgamma2 regulates lipogenesis and lipid accumulation in steatotic hepatocytes. Am J Physiol Endocrinol Metab 288: E1195-E1205, 2005.
24. Gavrilova O, Haluzik M, Matsusue K, Cutson JJ, Johnson L, Dietz KR, Nicol CJ, Vinson C, Gonzalez FJ and Reitman ML: Liver peroxisome proliferator-activated receptor gamma contributes to hepatic steatosis, triglyceride clearance, and regulation of body fat mass. J Biol Chem 278: 34268-34276, 2003.

25. Forman BM, Tontonoz P, Chen J, Brun RP, Spiegelman BM and Evans RM: 15-Deoxy-delta 12, 14-prostaglandin J2 is a ligand for the adipocyte determination factor PPAR gamma. Cell 83 803-812, 1995 .

26. Maggiora M, Oraldi M, Muzio G and Canuto RA: Involvement of PPAR $\alpha$ and PPAR $\gamma$ in apoptosis and proliferation of human hepatocarcinoma HepG2 cells. Cell Biochem Funct 28: 571-577, 2010.

27. Lessard SJ, Rivas DA, Chen ZP, Bonen A, Febbraio MA, Reeder DW, Kemp BE, Yaspelkis BB III and Hawley JA: Tissue-specific effects of rosiglitazone and exercise in the treatment of lipid-induced insulin resistance. Diabetes 56: 1856-1864, 2007.

28. Djaouti L, Jourdan T, Demizieux L, Chevrot M, Gresti J, Vergès B and Degrace P: Different effects of pioglitazone and rosiglitazone on lipid metabolism in mouse cultured liver explants. Diabetes Metab Res Rev 26: 297-305, 2010.

29. Morán-Salvador E, López-Parra M, García-Alonso V, Titos E, Martínez-Clemente M, González-Périz A, López-Vicario C, Barak Y, Arroyo $\mathrm{V}$ and Clària $\mathrm{J}$ : Role for PPAR $\gamma$ in obesity-induced hepatic steatosis as determined by hepatocyte and macrophage-specific conditional knockouts. FASEB J 25: 2538-2550, 2011.

30. Sugii S, Olson P, Sears DD, Saberi M, Atkins AR, Barish GD, Hong SH, Castro GL, Yin YQ, Nelson MC, et al: PPARgamma activation in adipocytes is sufficient for systemic insulin sensitization . Proc Natl Acad Sci USA 106: 22504-22509, 2009.

31. Hevener AL, He W, Barak Y, Le J, Bandyopadhyay G, Olson P, Wilkes J, Evans RM and Olefsky J: Muscle-specific Pparg deletion causes insulin resistance. Nat Med 9: 1491-1497, 2003.

32. Norris AW, Chen L, Fisher SJ, Szanto I, Ristow M, Jozsi AC, Hirshman MF, Rosen ED, Goodyear LJ, Gonzalez FJ: Musclespecific PPARgamma-deficient mice develop increased adiposity and insulin resistance but respond to thiazolidinediones. J Clin Invest 112: 608-618, 2003

33. Puigserver P, Rhee J, Donovan J, Walkey CJ, Yoon JC, Oriente F, Kitamura Y, Altomonte J, Dong H, Accili D and Spiegelman BM: Insulin-regulated hepatic gluconeogenesis through FOXO1-PGC-1alpha interaction. Nature 423: 550-555, 2003.

34. Samuel VT, Liu ZX, Qu X, Elder BD, Bilz S, Befroy D, Romanelli AJ and Shulman GI: Mechanism of hepatic insulin resistance in non-alcoholic fatty liver disease. J Biol Chem 279: 32345-32353, 2004

35. Samuel VT, Liu ZX, Wang A, Beddow SA, Geisler JG, Kahn M, Zhang XM, Monia BP, Bhanot S and Shulman GI: Inhibition of protein kinase Cepsilon prevents hepatic insulin resistance in nonalcoholic fatty liver disease. J Clin Invest 117: 739-745, 2007.

36. Deushi M, Nomura M, Kawakami A, Haraguchi M, Ito M, Okazaki M, Ishii $\mathrm{H}$ and Yoshida M: Ezetimibe improves liver steatosis and insulin resistance in obese rat model of metabolic syndrome. FEBS Lett 581: 5664-5670, 2007.

37. Nomura M, Ishii H, Kawakami A and Yoshida M: Inhibition of hepatic Niemann-Pick C1-like 1 improves hepatic insulin resistance. Am J Physiol Endocrinol Metab 297: E1030-E1038, 2009.

38. Henkel J, Neuschäfer-Rube F, Pathe-Neuschäfer-Rube A and Püschel GP: Aggravation by prostaglandin E2 of interleukin-6-dependent insulin resistance in hepatocytes. Hepatology 50: 781-790, 2009.

39. Chen J, Liu D, Bai Q, Song J, Guan J, Gao J, Liu B, Ma X and Du Y: Celecoxib attenuates liver steatosis and inflammation in non-alcoholic steatohepatitis induced by high-fat diet in rats. Mol Med Rep 4: 811-816, 2011.

40. Boden G, She P, Mozzoli M, Cheung P, Gumireddy K, Reddy P, Xiang $X$, Luo $Z$ and Ruderman N: Free fatty acids produce insulin resistance and activate the proinflammatory nuclear factor-kappaB pathway in rat liver. Diabetes 54: 3458-3465, 2005.

41. Tosello-Trampont AC, Landes SG, Nguyen V, Novobrantseva TI and Hahn YS: Kupffer cells trigger nonalcoholic steatohepatitis development in diet-induced mouse model through tumor necrosis factor- $\alpha$ production. J Biol Chem 287: 40161-40172, 2012. 